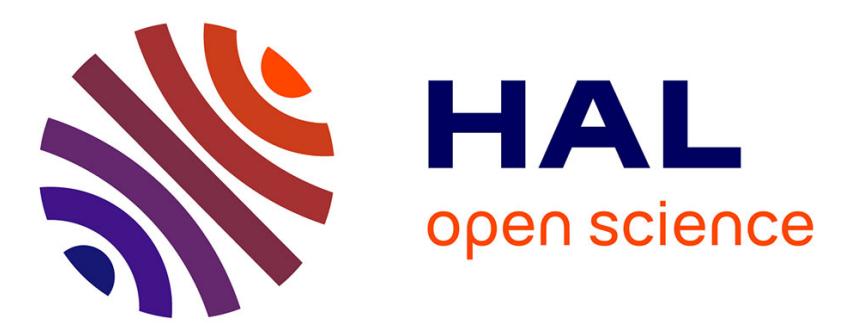

\title{
Mechanical properties of boron nitride thin films prepared by atomic layer deposition
}

Matthieu Weber, Emerson Coy, Igor Iatsunskyi, Luis Yate, Philippe Miele, Mikhael Bechelany

\section{- To cite this version:}

Matthieu Weber, Emerson Coy, Igor Iatsunskyi, Luis Yate, Philippe Miele, et al.. Mechanical properties of boron nitride thin films prepared by atomic layer deposition. CrystEngComm, 2017, 19 (41), pp.6089 - 6094. 10.1039/c7ce01357d . hal-01671663

\section{HAL Id: hal-01671663 \\ https://hal.umontpellier.fr/hal-01671663}

Submitted on 10 Jun 2021

HAL is a multi-disciplinary open access archive for the deposit and dissemination of scientific research documents, whether they are published or not. The documents may come from teaching and research institutions in France or abroad, or from public or private research centers.
L'archive ouverte pluridisciplinaire HAL, est destinée au dépôt et à la diffusion de documents scientifiques de niveau recherche, publiés ou non, émanant des établissements d'enseignement et de recherche français ou étrangers, des laboratoires publics ou privés. 


\section{Mechanical properties of boron nitride thin films prepared by atomic layer deposition}

Received 00th January 20xx, Accepted 00th January 20xx

DOI: $10.1039 / \times 0 \times x 00000 x$

\author{
Matthieu Weber ${ }^{a}$, Emerson Coy $^{b}$, Igor latsunskyi ${ }^{b *}$, Luis Yate ${ }^{c}$, Philippe Miele ${ }^{a}$ and Mikhael \\ Bechelany ${ }^{a^{*}}$
}

www.rsc.org/

Abstract. Due to their wide bandgap, boron nitride (BN) thin films are the focus of interest for their potential applications in microelectronic devices. The reliability of these devices is essential and is directly linked to the mechanical properties of the films used for their fabrication. Herein, an atomic layer deposition (ALD) process based on sequential pulses of $\mathrm{BBr}_{3}$ and $\mathrm{NH}_{3}$ at $750^{\circ} \mathrm{C}$ is used in order to prepare $\mathrm{BN}$ thin films. We report the main physicochemical properties of the films using various analytical methods, and we perform nanoindentation experiments in order to determine the elastic modulus and the hardness. Next, we annealed the films at 1000 and $1350^{\circ} \mathrm{C}$ in order to gain understanding on the relation between the annealing temperature, the microstructure obtained and the resulting mechanical properties. Although the hardness of the films presented similar values of $5 \pm 1 \mathrm{GPa}$ for all temperatures, it has been found that the elastic modulus increases up to $150 \pm 9 \mathrm{GPa}$ when applying an annealing treatment of $1350^{\circ} \mathrm{C}$ which represents a $37 \%$ improvement compared to the initial film prepared at $750^{\circ} \mathrm{C}$.

Boron nitride is a III-V material exhibiting exceptional physical and chemical properties that can be applied in various fields, from photonics to high temperature furnaces. $\frac{1-3}{\text { In }}$ the last decade, nanometer-thin films of boron nitride became the focus of interest for their potential application in semiconductor devices. For example, they could be used as dielectric layers for graphene based electronics. 4,5

The thin films used in the fabrication of microelectronic integrated circuits must perform their electronic and magnetic functions, but they must present certain chemical and mechanical properties as well. The reliability of microelectronic devices is essential, they are expected to present structural integrity over their lifetime, and mechanical failures shall not occur. Thus, these materials, though not

\footnotetext{
a. Institut Européen des Membranes, IEM-UMR 5635 ENSCM, UM, CNRS, Université de Montpellier, Place Eugène Bataillon, 34095 Montpellier Cedex 5, France

b. NanoBioMedical Centre, Adam Mickiewicz University in Poznan, 61-614,

Umultowska str. 85 Poznan, Poland

c. CIC biomaGUNE, Paseo Miramón 182, 20014, San Sebastián, Spain

d. *corresponding authors: Mikhael Bechelany: mikhael.bechelany@umontpellier.fr, phone: +33467149167, Fax: +33467149119

and Igor latsunskyi: yatsunskiy@gmail.com

$\S$ Supporting Information: Experimental section, TEM image of an annealed sample See DOI: $10.1039 / x 0 x x 00000$
}

selected exclusively for their mechanical properties, must provide adequate resistance to the mechanical forces that arise in these applications. $\underline{6}$ Elastic modulus (Er) is a material property related to atomic bonding, which characterizes its stiffness. It represents one of the most used material constants in microelectronic devices. Hardness $(\mathrm{H})$ depicts the ability of a material to resist deformation. As it is related to the elastoplastic response of a solid material under external loads, it represents an excellent indicator for material resistance to wear, scratch and deformation failure. $\frac{7}{}$

Boron nitride films can be prepared using many manufacturing techniques, such as mechanical exfoliation, $\underline{8}$ chemical vapor deposition, $\underline{\underline{9}-11}$ ion-beam-enhanced deposition, $\underline{\underline{12}}$ reactive ion plating, $\underline{13}$ or magnetron sputtering. $\underline{14}$ However, these technologies often present limitations in terms of conformality of the depositions, and they may require the use of energetic ions that can damage the substrates.

Atomic layer deposition (ALD) is a thin film deposition technique based on chemical surface reactions allowing for the preparation of high quality materials, with high uniformity, precise growth control, and excellent conformality. $\frac{15-17}{17}$ This route is currently used for the most challenging thin-film deposition applications such as microelectronics, as it is used for the preparation of high-k oxides gates. $\underline{16}, \underline{18}$ Concerning the characterization of thin films prepared by ALD in terms of mechanical properties, some recent efforts have carried out on oxide materials. Ylivaara et al. reported elastic modulus of $170 \mathrm{GPa}, \underline{19}$ and Tripp et al. measured similar elastic modulus of 168-182 GPa and Berkovitch hardness of $12 \mathrm{GPa}$, both teams focusing on $300 \mathrm{~nm}$ thick $\mathrm{Al}_{2} \mathrm{O}_{3}$ films. 20 Tapily et al. reported a hardness of $9.5 \pm 2 \mathrm{GPa}$ and a modulus of $220 \pm 40 \mathrm{GPa}$ for ALD $\mathrm{HfO}_{2}$ films. $\underline{21}$ Yuan et al. investigated the hardness of $\sim 500 \mathrm{~nm}$ thick ZnO films, which was found to be comprised between 5 and $8 \mathrm{GPa}$, depending on the crystallinity. $\underline{22}$ Jian and Lee measured $\mathrm{H}$ and $\mathrm{Er}$ for $\mathrm{ZnO}$ thin films which thickness was about $200 \mathrm{~nm}$, and the values found were respectively 10.3 GPa and $168.6 \mathrm{GPa} . \underline{23}$

Recently, several studies reported the synthesis of boron nitride thin films by ALD. $\underline{24-28}$ Although the main physicochemical properties, the electrical performances and the low leakage current density of BN ALD films have been reported,, 26 these studies did not include the investigation of the mechanical properties of the films. 
Herein, we used an ALD process in order to prepare BN thin films and study their mechanical properties. We report the main physico-chemical properties of the films using various analytical methods, and we perform indentation testing at the nanometer scale in order to determine the elastic modulus and the hardness. Furthermore, we annealed the films at 1000 and $1350^{\circ} \mathrm{C}$ in order to gain understanding on the relation between the annealing temperature, the microstructure obtained and the resulting mechanical properties.

An ALD process based on boron tribromide $\left(\mathrm{BBr}_{3}\right)$ and ammoniac $\left(\mathrm{NH}_{3}\right)$ at $750^{\circ} \mathrm{C}$ has been developed in order to synthesize $\mathrm{BN}$ thin films (see Supporting information). The sequential exposures of $\mathrm{BBr}_{3}$ and $\mathrm{NH}_{3}$ were separated by argon purges. Briefly, the ALD cycle consisted of $0.1 \mathrm{~s}$ pulse of $\mathrm{BBr}_{3}$ followed by $5 \mathrm{~s}$ exposure, $10 \mathrm{~s}$ purge, $5 \mathrm{~s}$ pulse of $\mathrm{NH}_{3}$ and $10 \mathrm{~s}$ purge to finish the cycle. The linearity of the growth depicted in Figure 1 demonstrates the successful ALD process.
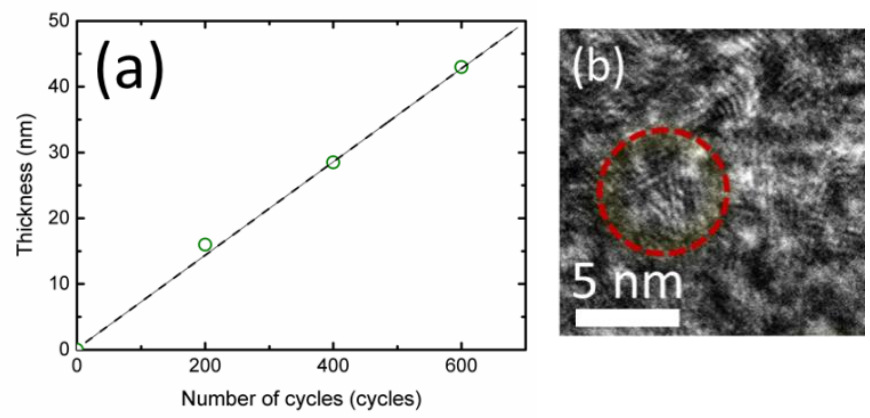

Figure 1. (a) Thickness of the $\mathrm{BN}$ film as a function of the number of ALD cycles, as measured by spectroscopic ellipsometry. The line serves as guide to the eyes. (b) High resolution TEM image of a $\sim 25 \mathrm{~nm}$ thick BN film prepared by ALD.

As measured by spectroscopic ellipsometry (SE), the saturated growth rate of the ALD process was $0.08 \mathrm{~nm} /$ cycle, which is in the same order of magnitude that the ones measured by other authors. $\underline{24}, \underline{26}, \underline{29}$ Our group has previously shown that this process based on self-limiting chemical reactions results in conformal and high quality BN films. More details about this ALD process can be found elsewhere. $\frac{30}{}$ Several analytical methods have been used to characterize the physico-chemical properties of the films ( $25 \mathrm{~nm}$ thick) prepared at $750^{\circ} \mathrm{C}$. XRay photoelectron spectroscopy (XPS) was used to determine the chemical composition. The films obtained showed near stoichiometric (1.1:0.9) contents of $\mathrm{B}$ and $\mathrm{N}$ with a clear $\mathrm{BN}$ structure, evidenced by the binding energy of $B$ 1s $(190.3 \mathrm{eV})$ and $\mathrm{N}$ 1s $(398.0 \mathrm{eV})$. The atomic concentrations found were $4 \pm 3 \%$ and $7 \pm 3 \%$, for $\mathrm{C}$ and $\mathrm{O}$, respectively, and no $\mathrm{Br}$ was found in the films (at the detection limit). X-Ray Diffraction (XRD) and Transmission Electron Microscopy (TEM) measurements have shown that the films present a turbostratic microstructure, and the presence of small areas of 5- $7 \mathrm{~nm}$ of BN planes of hexagons have been observed (see Figure $1 \mathrm{~b}$ ). A mass density value of $2.2 \pm 0.3 \mathrm{~g} / \mathrm{cm}^{3}$ has been extracted from X-Ray reflectometry (XRR) measurements. Atomic force microscopy (AFM) has been performed in order to determine the RMS roughness of the deposited films, and a value of $0.9 \pm 0.3 \mathrm{~nm}$ has been measured. The growth-per-cycle, $C$ and $O$ contents, mass density, and roughness values are given in Table S1 (Supporting Information).

Next, in order to study the mechanical properties of the films, we performed nanoindentation measurements. The nanoindentation method enables the extraction of two main pieces of information: the universal hardness, $H$, and the reduced modulus of elasticity, $\mathrm{Er}$, which are determined from the nanoindentation load-displacement curves by the Oliver-Pharr method (see Experimental section). The method involves making a small indentation in the film (usually with a Berkovich indenter presenting a triangular pyramid geometry), while continuously recording the indentation load and the displacement during one complete cycle of loading and unloading. $\frac{31}{}$ Figure 2 depicts a typical nanoindentation loading curve for a $\sim 80 \mathrm{~nm}$ thick BN film prepared at $750^{\circ} \mathrm{C}$ by ALD.

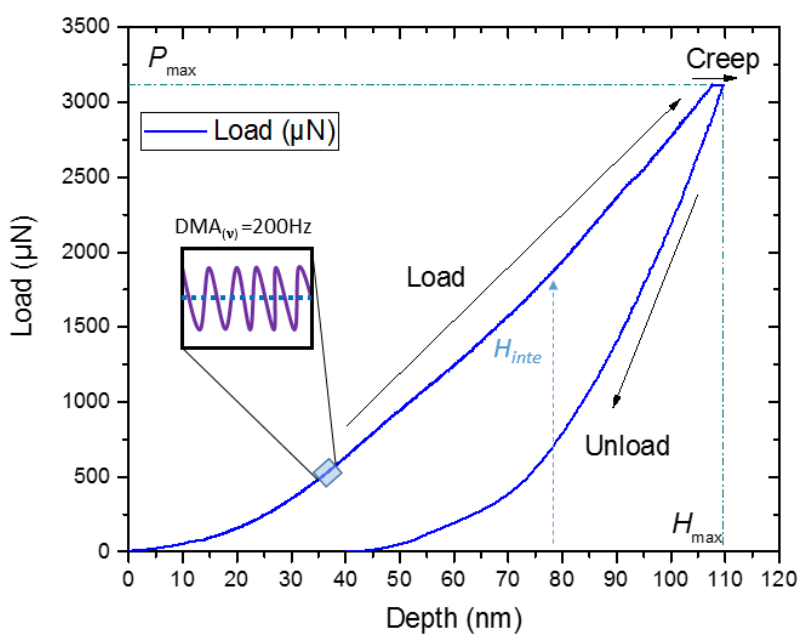

Figure 2. Nanoindentation loading curve for a BN film prepared at $750^{\circ} \mathrm{C}$ by ALD. The film was $\sim 80 \mathrm{~nm}$ thick and the substrate used was a $\mathrm{Si}(100)$ wafer.

The modulus of elasticity $\mathrm{Er}$ and hardness $\mathrm{H}$ obtained were $109 \pm 10 \mathrm{GPa}$ and $5.3 \pm 0.6 \mathrm{GPa}$, respectively. Although no results have been reported on the mechanical properties of turbostratic BN thin films to our knowledge, our results can be compared to the ones reported for hexagonal BN thin films.

Previous works have reported that hexagonal $\mathrm{BN}$ monolayer has a bulk modulus around $160 \mathrm{GPa}, \underline{32-34}$ which is in the same order of magnitude than the value we measured for turbostratic BN in our study. Concerning crystalline BN films, $\mathrm{Er}$ values between 420 and 505 GPa have been obtained on nanocrystalline BN films (400 $\mathrm{nm}$ thick) prepared by pulsed laser deposition. $\frac{35}{5}$ Nanoindentation measurements yielded hardness values for cubic BN films up to $60-70 \mathrm{GPa}$ (700 nm thick). $\frac{36}{}$ Jiang et al. studied the mechanical properties of cubic BN films ( $2 \mu \mathrm{m}$ thick) prepared by CVD using the same OliverPharr method. $\underline{37}$ Hardness values from 25 to $53 \mathrm{GPa}$ and 
effective Young modulus of $600 \pm 100 \mathrm{GPa}$ have been measured.

These values are substantially higher than the ones measured for our ALD films, but they were performed on crystalline BN film. It is indeed logical that the cubic phase present better mechanical properties than the turbostratic phase. In addition, one has to precise that the $E$ value approaches the property of the substrate when the penetration depth increases, and that the $600 \mathrm{GPa}$ value measured by Jiang et al. was obtained by extending the curve averaged from the experimental data to zero penetration depth. $\underline{37}$

The results we obtained for BN ALD films are in the same order of magnitude as the mechanical properties measured for $\mathrm{ZnO}$, $\mathrm{Al}_{2} \mathrm{O}_{3}$ and $\mathrm{HfO}_{2}$ films prepared by ALD. $\underline{20-22}$ These data provide input for the design of semiconductor devices such as microelectronic chips and micro electro mechanical systems (MEMS) with ALD of $\mathrm{BN}$, and can be of use for other applications as well.
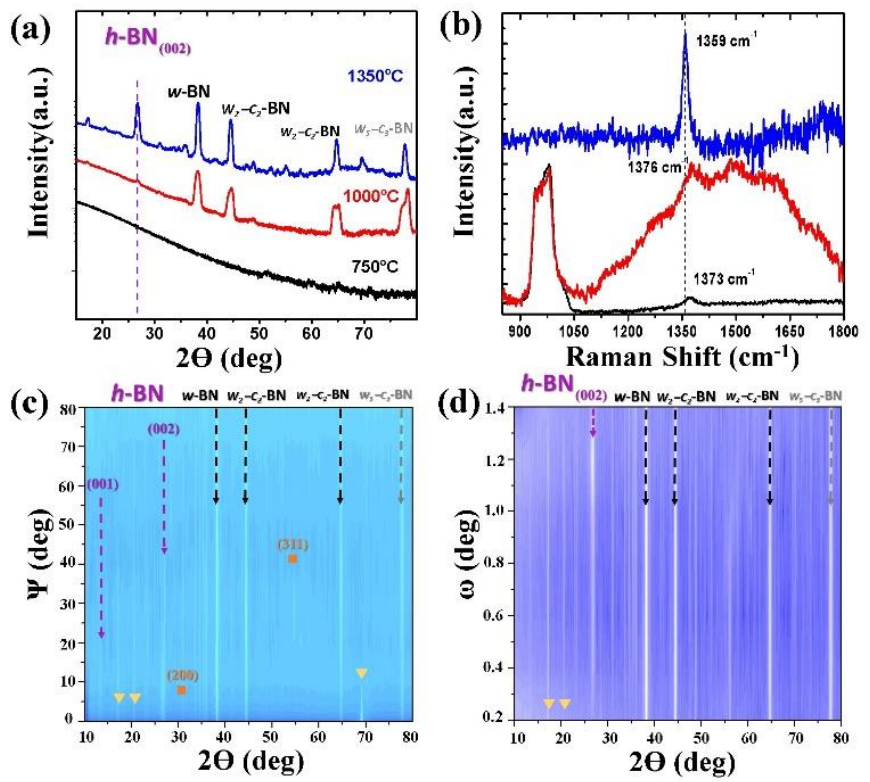

Figure 3. (a) XRD patterns of $\mathrm{BN}$ films prepared at $750^{\circ} \mathrm{C}$, as prepared and annealed at 1000 and $1350^{\circ} \mathrm{C}$. The peaks originated from h-BN (002) are shown with the purple line. (b) Raman spectroscopy of $\mathrm{BN}$ films prepared at $750^{\circ} \mathrm{C}$, asprepared and annealed at 1000 and $1350^{\circ} \mathrm{C}$. The $\mathrm{BN}$ films were $80 \mathrm{~nm}$ thick and the substrates were silicon with a native oxide layer. (c) $2 \theta$ scans at different $\Psi$ angle (0-80 degrees). (d) $2 \theta$ scans performed at different penetrations of the incident angle $(\omega)$. The $\boldsymbol{\nabla}$ and $\boldsymbol{\nabla}$ symbols represent the Zinc blende and spurious phases, respectively.

It is known in the literature that the mechanical properties are generally linked to the microstructure of the films,, 38 and that this latter can be modified by high temperature treatments. In fact, several studies have shown the crystallographic changes of boron nitride films. Starting from imperfect turbostratic microstructures, the heat treatments typically promoted the ordering of $\mathrm{BN}$ structures leading to crystalline hexagonal $\mathrm{BN} . \underline{11}, \underline{39}, \underline{40}$ Thus, in order to gain understanding on the relation between the annealing temperature and the resulting mechanical properties, we annealed the films at $1000^{\circ} \mathrm{C}$ and $1350^{\circ} \mathrm{C}$ (for 3 hours). Aiming to reveal the phase transformations after annealing, we performed XRD and Raman spectroscopy measurements. First, XRD measurements have been carried out for the sample prepared at $750^{\circ} \mathrm{C}$ and for the annealed samples at 1000 and $1350^{\circ} \mathrm{C}$, in order to confirm the crystallographic changes. The as prepared sample showed no features, as depicted in Figure 3a. This indicates that the films present nanocrystal size smaller than the XRD detection limit or even amorphous phase. In fact, as can be seen in Figure 1b, ALD of BN typically results in films presenting a turbostratic microstructure with small nanocrystals. $\underline{24}, 30,41, \underline{42}$ However, the high temperature annealing treatments resulted in XRD patterns showing different slidings in the structures of $\mathrm{BN}$, and peaks characteristic from hexagonal BN (h-BN), wurtzite (w-BN), w2$\mathrm{C} 2-\mathrm{BN}$ and $\mathrm{w} 8 \mathrm{c} 3-\mathrm{BN}$ were found for the samples annealed at 1000 and $1350^{\circ} \mathrm{C}$, confirming the phase transformation. $\frac{43}{3}$ These new visible microstructures are attributed to the evolution of the original turbostratic microstructure after the high temperature treatments, that allowed the sliding and buckling of BN sheets. $\underline{43-45}$

Next, we carried out Raman spectroscopy measurements in order to provide information about the vibrational modes in the $\mathrm{BN}$ systems obtained. Figure $3 \mathrm{~b}$ shows the Raman spectroscopy of $\mathrm{BN}$ samples prepared at $750^{\circ} \mathrm{C}$, and annealed at 1000 and $1350^{\circ} \mathrm{C}$. It is known that the $E_{2 g}$ vibrational mode for bulk h-BN appears at approximately $1366 \mathrm{~cm}^{-1}$. 46 The Raman spectrum of the as prepared sample at $750^{\circ} \mathrm{C}$ shows a weak peak of $\mathrm{BN}$ at $1373 \mathrm{~cm}^{-1}$, indicating that the prepared $\mathrm{BN}$ layer was amorphous with a small ratio of hexagonal crystalline phase. For the annealed sample at $1000^{\circ} \mathrm{C}$, the intensity of the BN peak increased, indicating the amorphousto-crystalline phase transition. A broad Raman peak between 900 and $1100 \mathrm{~cm}^{-1}$ corresponds to the superposition of three transverse optical phonons ( 2TO (X), 2TO (W) and 2TO (L)). 47 However, a broad peak around $1400 \mathrm{~cm}^{-1}$ consisting of at least 4 components $\left(1376,1500,1620\right.$ and $\left.1720 \mathrm{~cm}^{-1}\right)$ also appears. This might be explained by the presence of various $\mathrm{BN}$ phases in the material. For the sample annealed at $1350^{\circ} \mathrm{C}$, only one main peak at $1359 \mathrm{~cm}^{-1}$ is visible, which corresponds to the $\mathrm{h}$ BN phase, suggesting that the prepared layer is fully crystalline. 
Prior to nanomechanical analysis, it is important to understand and investigate the high temperature mixture of phases observed in the $1350^{\circ} \mathrm{C}$ sample. Therefore, we performed long XRD diffraction experiments in non-geometrical configurations. These experiments enable us to investigate the possible stress induced in the films and the ordering of the phases. From Figure 3(c) where the $\Psi$ angle is analyzed, it is clear that the $h$-BN phase, although rapidly disappearing with the increment of $\Psi$, is still visible at $40^{\circ} \Psi$, showing that even though the turbostratic configuration should promote randomly oriented $h$-BN crystals, this phase is somehow aligned perpendicularly to the substrate interface. Additionally, as expected by the sliding and buckling of the BN, the $\mathrm{w} 2-\mathrm{c} 2-\mathrm{BN}$ and $\mathrm{w} 8 \mathrm{c} 3-\mathrm{BN}$ phases are randomly distributed, as demonstrated by their strong presence even at $90^{\circ} \Psi$. In addition, the presence of a Zinc blend BN phase is found. Interestingly, all phases are stress free, as evidenced by the constant $d$ spacing and $2 \theta$ angle. These results suggest that the phase composition is not homogenous in the high temperature sample. Therefore, in order to investigate different penetration depths, Grazing-Incidence XRD experiments were performed at different $\omega$ angle. Figure $3(d)$ shows high intensity peaks for the w2-c2-BN and w8c3-BN at angles as low as $0.2^{\circ} \omega$. On the other hand, the $h$-BN phase intensity increases regularly with the $\omega$ angle, suggesting that the highest concentration of this phase is present in the deepest part of the film, whereas the secondary phases are present everywhere in the sample.

From these analyses, it is clear that the sample annealed at $1350^{\circ} \mathrm{C}$ has a very complex phase diagram, and its morphology should reflect such changes. SEM and AFM analysis have been performed to confirm this assumption. In Figure 4(a), both SEM and AFM micrographs are shown for the whole set of samples. The roughness of the samples remains close to $5 \mathrm{~nm}$ for all the samples, whereas a large change in morphology is observed in the $1350^{\circ} \mathrm{C}$ sample. Large areas of the film have reconstructed in complex microstructures. Even if no stoichiometric changes were observed from XPS studies, the clear differences in contrast seen in the SEM images suggest several changes in electronic structures, which points to different phases of $\mathrm{BN}$.

Next, in order to depict the relation between the mechanical properties and the microstructure, we performed the nanoindentation experiments on the annealed films. The values obtained after the annealing treatment at $1000^{\circ} \mathrm{C}$ were $121 \pm 12 \mathrm{GPa}$ and $6.2 \pm 0.5 \mathrm{GPa}$ for the modulus of elasticity $\mathrm{Er}$ and hardness $\mathrm{H}$ obtained, respectively. Considering the sample on which a heat treatment at $1350^{\circ} \mathrm{C}$ has been performed, values of $150 \pm 8 \mathrm{GPa}$ (for $\mathrm{Er}$ ) and $5.5 \pm 0.5 \mathrm{GPa}$ (for $\mathrm{H}$ ) have been measured. The elastic modulus and hardness obtained for $\mathrm{BN}$ films prepared at $750^{\circ} \mathrm{C}$, with an annealing at $1000^{\circ} \mathrm{C}$ and $1350^{\circ} \mathrm{C}$ are summarized in the Figure 4. (a)
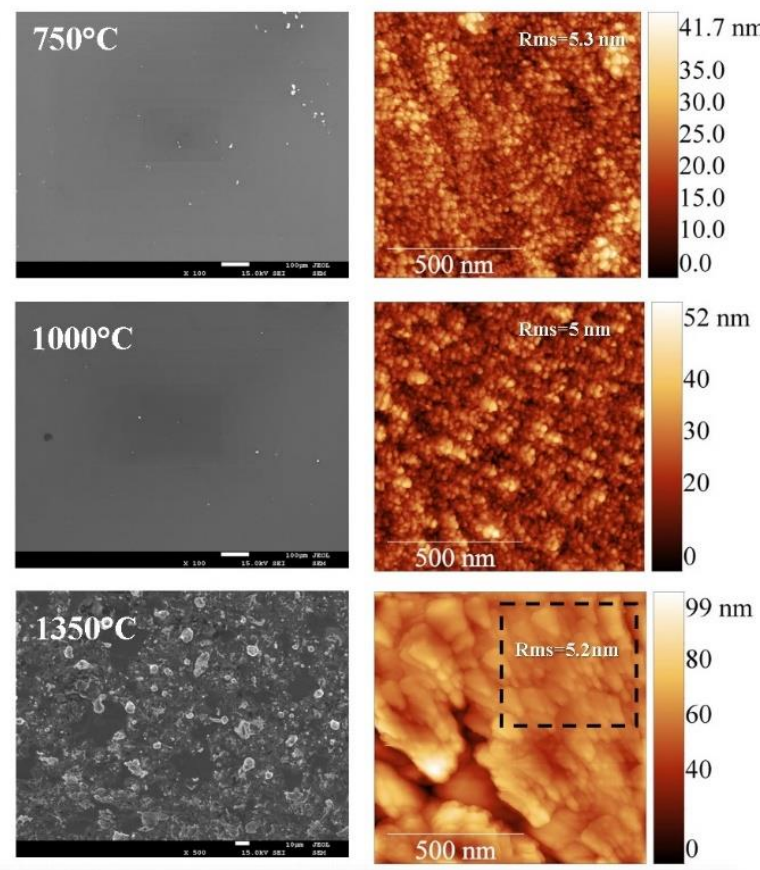

(b)

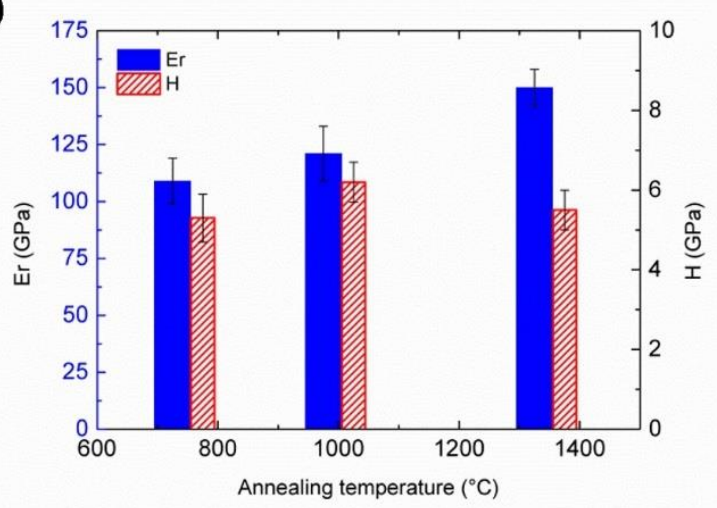

As can be depicted from these results, whereas the hardness is not substantially affected, a strong increase of the modulus of elasticity is obtained when applying the temperature treatments, which can be attributed to the crystalline phase transition of the BN films. The increase in elastic modulus and hardness in the films after annealing might be correlated with the microstructural evolution we observed, but also to possible shifts in the phase composition and grain size as a consequence of the annealing process.

Figure 4. (a) SEM and AFM surface micrographs of the samples prepared at 750,1000 and $1350^{\circ} \mathrm{C}$. The insets show the roughness of the samples (dashed area in $1350^{\circ} \mathrm{C}$ shows the area where the RMS was taken). (b) Elastic modulus (Er) and hardness $(\mathrm{H})$ obtained for BN films ( $80 \mathrm{~nm}$ thick) prepared by ALD at $750^{\circ} \mathrm{C}$ without heat treatment, and with heat treatments (annealing) at $1000^{\circ} \mathrm{C}$ and $1350^{\circ} \mathrm{C}$. The substrates were $\mathrm{Si}(100)$ wafers.

In particular, the elastic modulus increases up to $150 \pm 9 \mathrm{GPa}$ when applying an annealing treatment of $1350^{\circ} \mathrm{C}$, which is a 
significant $37 \%$ enhancement compared to the initial film prepared at $750^{\circ} \mathrm{C}$. The mechanical properties obtained are therefore very promising and can be used as a useful comparison point for future studies and for the design of micro devices.

\section{Conclusions}

In this work, we reported the mechanical properties of $\mathrm{BN}$ thin films prepared by ALD. The process was based on $\mathrm{BBr}_{3}$ and $\mathrm{NH}_{3}$ at $750^{\circ} \mathrm{C}$. The main physicochemical properties of the films have been determined by various analytical methods, and we performed nanoindentation loading experiments in order to determine the elastic modulus and the hardness of the films. Films grown at $750^{\circ} \mathrm{C}$ presented an elastic modulus of $109 \pm 10$ $\mathrm{GPa}$ and a Berkovich hardness of $5.3 \pm 0.6 \mathrm{GPa}$. These results are in line with other $E$ and $H$ measured for other ALD materials reported in the literature. Furthermore, in order to gain understanding on the relation between heat treatments and the resulting mechanical properties, we annealed the films at $1000^{\circ} \mathrm{C}$ and $1350^{\circ} \mathrm{C}$ and performed again the nanoindentation experiments. It has been found that the elastic modulus increased up to $150 \pm 9 \mathrm{GPa}$ when applying a heat treatment of $1350^{\circ} \mathrm{C}$, denoting a considerable enhancement of the mechanical properties compared to the initial film prepared at $750^{\circ} \mathrm{C}$. XRD and Raman spectroscopy measurements were used to confirm the phase transition. The results presented in this work can be used as a useful comparison point for future studies on the mechanical properties of ALD films, and open prospects for the use of BN ALD films in electronic devices and other applications where mechanical properties are crucial.

\section{Notes and references}

¥ This work was supported by the French Research Program ANR BONALD. The supports of the COST Action "HERALD", a European cooperation program, is acknowledged.

1. J. Eichler and C. Lesniak, Journal of the European Ceramic Society, 2008, 28, 1105-1109.

2. S. Arya and A. D'amico, Thin Solid Films, 1988, 157, 267-282.

3. R. Dahal, J. Li, S. Majety, B. Pantha, X. Cao, J. Lin and H. Jiang, Applied physics letters, 2011, 98, 211110.

4. K. H. Lee, H.-J. Shin, J. Lee, I.-y. Lee, G.-H. Kim, J.-Y. Choi and S.W. Kim, Nano letters, 2012, 12, 714-718.

5. C. R. Dean, A. F. Young, I. Meric, C. Lee, L. Wang, S. Sorgenfrei, K. Watanabe, T. Taniguchi, P. Kim and K. L. Shepard, Nature nanotechnology, 2010, 5, 722-726.

6. H. Morkoç, Handbook of nitride semiconductors and devices, Materials Properties, Physics and Growth, John Wiley \& Sons, 2009.

7. M. Ohring, Materials Science of Thin Films, 2002, 711-782.
8. Y. Lin, T. V. Williams and J. W. Connell, The Journal of Physical Chemistry Letters, 2009, 1, 277-283.

9. Y. Shi, C. Hamsen, X. Jia, K. K. Kim, A. Reina, M. Hofmann, A. L. Hsu, K. Zhang, H. Li, Z. Y. Juang, M. S. Dresselhaus, L. J. Li and J. Kong, Nano letters, 2010, 10, 4134-4139.

10. S. Matsumoto and W. Zhang, Japanese Journal of Applied Physics, 2000, 39, L442.

11. J.-S. Li, C.-R. Zhang, B. Li, F. Cao and S.-Q. Wang, Surface and Coatings Technology, 2011, 205, 3736-3741.

12. T. Ikeda, Applied physics letters, 1992, 61, 786-788.

13. D. McKenzie, D. Cockayne, D. Muller, M. Murakawa, S. Miyake, S. Watanabe and P. Fallon, Journal of applied physics, 1991, 70, 3007-3012.

14. M. Mieno and T. Yoshida, Japanese Journal of Applied Physics, 1990, 29, L1175.

15. S. M. George, Chemical reviews, 2009, 110, 111-131.

16. R. W. Johnson, A. Hultqvist and S. F. Bent, Materials today, 2014, 17, 236-246.

17. M. Leskelä and M. Ritala, Thin Solid Films, 2002, 409, 138-146.

18. J. Niinistö, K. Kukli, M. Heikkilä, M. Ritala and M. Leskelä, Advanced Engineering Materials, 2009, 11, 223-234.

19. O. M. Ylivaara, X. Liu, L. Kilpi, J. Lyytinen, D. Schneider, M. Laitinen, J. Julin, S. Ali, S. Sintonen and M. Berdova, Thin Solid Films, 2014, 552, 124-135.

20. M. K. Tripp, C. Stampfer, D. C. Miller, T. Helbling, C. F. Herrmann, C. Hierold, K. Gall, S. M. George and V. M. Bright, Sensors and Actuators A: Physical, 2006, 130, 419-429.

21. K. Tapily, J. E. Jakes, D. Stone, P. Shrestha, D. Gu, H. Baumgart and A. Elmustafa, Journal of The Electrochemical Society, 2008, 155, H545-H551.

22. N. Yuan, S. Wang, C. Tan, X. Wang, G. Chen and J. Ding, Journal of Crystal Growth, 2013, 366, 43-46.

23. R. Raghavan, M. Bechelany, M. Parlinska, D. Frey, W. Mook, A. Beyer, J. Michler and I. Utke, Applied physics letters, 2012, 100, 191912.

24. M. Snure, Q. Paduano, M. Hamilton, J. Shoaf and J. M. Mann, Thin Solid Films, 2014, 571, 51-55.

25. M. S. Driver, J. D. Beatty, O. Olanipekun, K. Reid, A. Rath, P. M. Voyles and J. A. Kelber, Langmuir, 2016, 32, 2601-2607.

26. H. Park, T. K. Kim, S. W. Cho, H. S. Jang, S. I. Lee and S.-Y. Choi, Scientific reports, 2017, 7, 40091.

27. J. Jones, B. Beauclair, O. Olanipekun, S. Lightbourne, M. Zhang, B. Pollok, A. Pilli and J. Kelber, Journal of Vacuum Science \& Technology A: Vacuum, Surfaces, and Films, 2017, 35, 01B139.

28. A. Hemmi, C. Bernard, H. Cun, S. Roth, M. Klöckner, T. Kälin, M. Weinl, S. Gsell, M. Schreck and J. Osterwalder, Review of Scientific Instruments, 2014, 85, 035101.

29. B. Mårlid, M. Ottosson, U. Pettersson, K. Larsson and J.-O. Carlsson, Thin Solid Films, 2002, 402, 167-171.

30. M. Weber, B. Koonkaew, S. Balme, I. Utke, F. Picaud, I. latsunskyi, E. Coy, P. Miele and M. Bechelany, ACS Applied Materials and Interfaces, 2017, 9, 16669-16678.

31. W. C. Oliver and G. M. Pharr, Journal of materials research, 1992, 7, 1564-1583.

32. A. Nag, K. Raidongia, K. P. Hembram, R. Datta, U. V. Waghmare and C. Rao, ACS nano, 2010, 4, 1539-1544.

33. D. Golberg, Y. Bando, Y. Huang, T. Terao, M. Mitome, C. Tang and C. Zhi, ACS nano, 2010, 4, 2979-2993.

34. Q. Peng, W. Ji and S. De, Computational Materials Science, 2012, 56, 11-17. 
35. G. Lehmann, P. Hess, S. Weissmantel, G. Reisse, P. Scheible and A. Lunk, Applied Physics A: Materials Science \& Processing, 2002, 74, 41-45.

36. P. Mirkarimi, D. Medlin, K. McCarty, D. Dibble, W. Clift, J. Knapp and J. Barbour, Journal of applied physics, 1997, 82, 1617-1625.

37. X. Jiang, J. Philip, W. Zhang, P. Hess and S. Matsumoto, Journal of applied physics, 2003, 93, 1515-1519.

38. S. Weissmantel, G. Reisse, B. Keiper and S. Schulze, Diamond and Related Materials, 1999, 8, 377-381.

39. T. Hagio, K. Nonaka and T. Sato, Journal of materials science letters, 1997, 16, 795-798.

40. M. Bechelany, S. Bernard, A. Brioude, D. Cornu, P. Stadelmann, C. Charcosset, K. Fiaty and P. Miele, The Journal of Physical Chemistry C, 2007, 111, 13378-13384.

41. A. Haider, C. Ozgit-Akgun, E. Goldenberg, A. K. Okyay, N. Biyikli and G. Brennecka, Journal of the American Ceramic Society, 2014, 97, 4052-4059.

42. J. Ferguson, A. Weimer and S. George, Thin Solid Films, 2002, 413, 16-25.

43. N. Xu, J. Li, B. Huang and B. Wang, RSC Advances, 2014, 4, 38589-38593.

44. A. Nagakubo, H. Ogi, H. Sumiya, K. Kusakabe and M. Hirao, Applied physics letters, 2013, 102, 241909.

45. C. He, L. Sun, C. Zhang, X. Peng, K. Zhang and J. Zhong, Physical Chemistry Chemical Physics, 2012, 14, 10967-10971.

46. R. V. Gorbachev, I. Riaz, R. R. Nair, R. Jalil, L. Britnell, B. D. Belle, E. W. Hill, K. S. Novoselov, K. Watanabe and T. Taniguchi, small, 2011, 7, 465-468.

47. I. latsunskyi, G. Nowaczyk, S. Jurga, V. Fedorenko, M. Pavlenko and V. Smyntyna, Optik-International Journal for Light and Electron Optics, 2015, 126, 1650-1655. 